\title{
Impact of Flavonoids on Cellular and Molecular Mechanisms Underlying Age-Related Cognitive Decline and Neurodegeneration
}

\author{
Emma Flanagan $^{1} \cdot$ Michael Müller $^{1} \cdot$ Michael Hornberger $^{1} \cdot$ David Vauzour $^{1}$
}

Published online: 27 April 2018

(C) The Author(s) 2018

\begin{abstract}
Purpose of Review This review summarises the most recent evidence regarding the effects of dietary flavonoids on age-related cognitive decline and neurodegenerative diseases.

Recent Findings Recent evidence indicates that plant-derived flavonoids may exert powerful actions on mammalian cognition and protect against the development of age-related cognitive decline and pathological neurodegeneration. The neuroprotective effects of flavonoids have been suggested to be due to interactions with the cellular and molecular architecture of brain regions responsible for memory.

Summary Mechanisms for the beneficial effects of flavonoids on age-related cognitive decline and dementia are discussed, including modulating signalling pathways critical in controlling synaptic plasticity, reducing neuroinflammation, promoting vascular effects capable of stimulating new nerve cell growth in the hippocampus, bidirectional interactions with gut microbiota and attenuating the extracellular accumulation of pathological proteins. These processes are known to be important in maintaining optimal neuronal function and preventing age-related cognitive decline and neurodegeneration.
\end{abstract}

Keywords Polyphenols $\cdot$ Memory $\cdot$ Alzheimer's disease $\cdot$ Signalling pathways $\cdot$ Microbiome

\section{Introduction}

Advances in medical science over the last century have resulted in a considerable increase in human life expectancy. Despite this positive outcome, with increasing age comes an increased susceptibility to chronic organ disease and decline of metabolic and immune functions with impact on the brain [1]. Although some decline in cognitive function does occur with normal ageing, there is also an increased age-associated risk neurodegenerative disorders of which Alzheimer's disease (AD) is the most prevalent. As such, with the global ageing population, the prevalence of dementia worldwide is estimated to double every 20 years, and expected to increase to 115 million affected individuals by 2050 [2]. Existing drug treatments for neurodegenerative conditions rarely curtail the

This article is part of the Topical Collection on Neurological Disease and Cognitive Function

David Vauzour

D.Vauzour@uea.ac.uk

1 Norwich Medical School, Faculty of Medicine and Health Sciences, University of East Anglia, Norwich NR4 7UQ, UK underlying disease processes, and consequently, there is an urgent need to develop alternative strategies to directly prevent, slow and even stop neurodegeneration. Lifestyle strategies such as nutritional interventions have potential to be a safe, cheap and effective alternative to protect against agerelated cognitive decline and neurodegeneration, resulting in significant personal and societal benefits [3]. In particular, there has been a growing recent focus on the potential for dietary flavonoids, plant-derived compounds found abundantly in fruit, vegetables, cocoa and certain beverages such as coffee and tea, to directly prevent pathological mechanisms underlying neurodegeneration $[4,5]$. This review aims to summarise the existing evidence in favour of dietary flavonoids as a viable alternative approach to directly impact cognitive decline and neurodegenerative disease, with a particular focus on $\mathrm{AD}$.

\section{Flavonoids, Age-Related Cognitive Decline and Neurodegeneration}

Even in the absence of pathological neurodegeneration, agerelated cognitive decline has been consistently demonstrated 
in studies involving both animals and humans. Alterations in cognition appear to occur predominantly in domains relating to storage of newly acquired information including short-term memory [6], working memory and executive function [7]. The overall reduced risk of cognitive decline that has been observed with higher intakes of fruit and vegetables is likely attributable to a higher intake of specific flavonoids [8]. In line with this, in middle-aged adults a higher total intake of flavonoids has been associated with better episodic memory and language performance [9], and greater cognitive performance at baseline with less decline at follow-up in non-demented older adults [10]. These findings have encouraged further investigation into specific flavonoids, their possible health benefits and the mechanisms by which they might exert these effects.

Berries have received particular attention for preventing age-related cognitive decline due to their considerably high concentrations of flavonoids. Blueberries are particularly rich in flavonoids, the most prevalent being anthocyanidins (delphinidin, cyanidin, petunidin, peonidin and malvidin), flavanols (catechin, epicatechin, procyanidins B type) and flavonols (quercetin and myricetin) [11]. In aged rodents, blueberry supplementation has been shown to improve spatial memory [12], object recognition memory [13] and inhibitory fear conditioning learning [14]. Blueberry appears to have a pronounced effect on short-term memory [15] and has also been shown to improve long-term reference memory following 8 weeks of supplementation in aged rats $[12,16]$. Regarding studies involving humans, a long-term prospective study of neurologically healthy older adults observed a greater intake of berry anthocyanidins related to a slower rate of cognitive decline and was associated with a 2.5-year delay in the onset of deficits [17]. In addition to berries, animal studies involving flavanols from cocoa and tea provide positive evidence that these flavonoids could also protect against cognitive decline. For example, (-)-epicatechin enhanced the retention of spatial memory in male C57BL/6 mice (8-10 weeks old), particularly in combination with exercise [18], and a 6month administration of green tea catechins in 14-month-old female C57BL/6 mice prevented spatial learning and memory decline [19].

Regarding pathological cognitive decline, approximately 60 to $80 \%$ of dementia cases are due to AD [20], affecting over than 25 million people globally [21]. AD is diagnosed based on a combination of clinical history, often provided by a close family member, and performance on neuropsychological testing with a particular focus on short-term memory performance. Mild cognitive impairment (MCI) is characterised by cognitive impairment in the absence of significant disruption to everyday function [22], and individuals diagnosed with $\mathrm{MCI}$ have an increased risk for progressing to $\mathrm{AD}[23,24]$. Several epidemiological studies have investigated the associations between higher intakes of dietary flavonoids and possible neuroprotective effects in the context of dementia. For example, higher intake of flavonoid-rich foods was associated with a significantly lower risk of dementia in a large cohort of older adults aged 65 years and over [25].

Gene mutations in encoding the amyloid precursor protein (APP) or presenilin (PS1 and PS2) [26], and more recently the $A P O E$ gene with the $E 4$ allele mutation, have been identified as significant genetic susceptibility predictors for $\mathrm{AD}$ [27], with over $60 \%$ of individuals affected by $\mathrm{AD}$ carrying the $A P O E 4$ variant compared to a much lower prevalence of $25-27 \%$ in the general population. The APOE4 genotype is associated with more rapid cognitive decline [28] and poorer performance even in neurologically healthy carriers [29]. The APOE4 genotype is also associated with an earlier age of disease onset [28] and a higher conversion rate to $\mathrm{AD}$ in individuals diagnosed with $\mathrm{MCI}$ [30]. Of particular relevance is emerging evidence suggesting that the APOE4 genotype may modify the beneficial effect of flavonoids on cognition and prevalence of AD. For example, a greater consumption of flavonoid-rich fruits and vegetables was associated with a decreased risk of dementia especially amongst APOE4 non-carriers in the Three-City cohort study [8]. By contrast, in the Kame project, a more frequent consumption of flavonoids-rich foods was suggested to delay the onset of AD particularly in APOE4 carriers [31]. As such, further investigation is required in order to elucidate the exact mechanisms by which the presence of the APOE4 mutation modulates the health benefits from dietary flavonoids.

Results from intervention studies involving humans are less prevalent. Previous acute human studies have shown that cocoa flavanol consumption improved working memory and attention $[32,33]$, significantly increased cerebral blood flow across the brain [34], particularly in the dentate gyrus [35], in healthy adults. A randomised, placebocontrolled trial of Concord grape juice in older adults with memory decline showed improvement on verbal encoding [36], and similar effects were observed with blueberry juice administered over 12 weeks [37]. Similarly, Desideri et al. (2012) also observed better verbal fluency performance in older individuals with MCI following consumption of a drink high in flavan-3-ol over only 8 weeks [38]. As such, the consumption of flavonoid-rich foods may have the potential to limit or even reverse agerelated cognitive decline. However, findings that lend support to the causal effects of dietary flavonoids on the prevention of age-related cognitive decline and dementia from interventional studies still remains sparse. Given the promising results from epidemiological and preclinical studies, further attention needs to be dedicated to determining the causality of flavonoid consumption on improving cognition and preventing dementia. 


\section{Mechanisms Underlying the Neuroprotective Effects of Flavonoids}

Despite the precise causes of cognitive decline remaining unclear, age-related neurodegeneration is considered to be underpinned by several interlinked cellular and molecular mechanisms, including cumulative damage due to chronic neuroinflammation, oxidative stress, impaired mitochondrial function, activation of neuronal apoptosis, deposition of aggregated proteins and excitotoxicity. The health-promoting effects of flavonoids have previously been attributed to their ability to reduce cell damage by directly scavenging free radical species, according to evidence from in vitro studies. However, the concentrations of flavonoids that have been found to exert such antioxidant activity are significantly higher than can be achieved through diet in humans. Furthermore, many flavonoids have very limited bioavailability as they are efficiently metabolised before being able to exert their antioxidant effects [39]. Recent evidence suggests that flavonoids at physiologically attainable concentrations may exert different activities which directly impact neurodegenerative disease-causing processes. The possible mechanisms by which flavonoids prevent against age-related neurodegeneration are explored in further detail here.

\section{Reduction of Neuropathological Protein Accumulation}

The neuropathological hallmarks of $\mathrm{AD}$ are the extracellular deposition of amyloid plaques and the intracellular accumulation of hyperphosphorylated tau proteins - a neuronal microtubule-associated protein regulated by phosphorylation of various protein kinases [40]. Most preclinical studies investigating the effects of flavonoids have focused on models where there is increased production of beta-amyloid $(A \beta)$, a small protein produced by the enzymatic cleavage of APP [41]. One way in which flavonoids may prevent the accumulation of $A \beta$ pathology is by preventing neuronal apoptosis triggered by neurotoxic processes through the inhibition of $\beta$ secretase (BACE-1) [42] and activation of $\alpha$-secretase (ADAM10) [43]. However, these in vitro studies involved flavonoid concentrations far greater than those encountered in vivo following a normal diet. In animal studies, epigallocatechin-3-gallate (EGCG) administered for 6 months significantly reduced cognitive decline and $\mathrm{A} \beta$ in an $\mathrm{AD}$ mouse model, [44] and green tea catechin administration improved spatial learning and memory in senescence-prone mice [45], the latter being associated with decreased in $A \beta$ accumulation and upregulation of proteins related to synaptic plasticity in the hippocampus. In addition, administration of a catechin-rich grape seed extract was associated with reduced cognitive decline in conjunction with decreased concentrations of $A \beta$ oligomers [46]. Similarly, administration of the citrus-derived flavone nobiletin in APP-SL 7-5 Tg mice was associated with reduced hippocampal accumulation of neurotoxic $A \beta$ proteins [47]. Mechanisms by which some flavonoids may prevent $A \beta$ plaque accumulation include inhibition of amyloid aggregation and fibrillization [46], either due to metal chelation activity [48] or through facilitating production of non-toxic oligomers [49], as well as the upregulation of $\alpha$ secretase through modulation of A disintegrin and metalloproteinaise domain-containing protein 10 (ADAM10) [50].

Despite these promising findings, it is important to note that the presence of $A \beta$ pathology and cognitive deficits are not always well correlated. For example, a recent study observed cognitive improvement following a polyphenol-rich diet without associated changes in classical AD neuropathology $[51 \bullet \cdot$. It is possible that some of the protective effects of flavonoids on age-related cognitive decline could instead be, at least in part, due to downstream processes from changes in $\mathrm{A} \beta$, such as tau phosphorylation and fibrillization. The development of neurofibrillary tangles could be inhibited by flavonoids such as (-)-epicatechin and hesperetin, through their promotion of protein kinase $\mathrm{B}$, or Akt, phosphorylation leading to reduced GSK3 $\beta$-driven hyperphosphorylation of tau $[52,53]$. As such, the benefits of dietary flavonoids in the context of AD may extend beyond interactions with processes underpinning neurotoxic $A \beta$ accumulation.

\section{Stimulation of Neuronal Signalling Pathways and Synaptic Plasticity}

Although the precise sites of the interactions between flavonoids and neuronal signalling pathways remain to be determined, based on existing evidence flavonoids may exert their effects through (1) modulating signalling cascades that control neuronal apoptosis; (2) modulating the expression of specific genes and (3) impacting mitochondrial activity [54]. In particular, current findings suggest that flavonoids impact on the extracellular signal-regulated kinase (ERK) pathway [52], which appears to be mediated by interactions with mitogenactivated protein kinase (MEK) 1 and 2, and potentially membrane receptors [55]. Evidence from in vitro studies has suggested that flavonoids increase the activation of ERK. For example, both the flavanol (-)-epicatechin [56] and the citrus flavanone hesperetin [57] were observed to activate ERK1/2 in cortical neurons at nanomolar concentrations, and submicromolar concentrations of EGCC were reported to restore ERK1/2 activities in 6-hydroxydopamine treated or serum-deprived neurons [58]. ERK activation often subsequently leads to the activation of the CREB transcription factor, considered critical in supporting synaptic plasticity [59] and controlling neuronal survival by regulating the expression of a number of important genes, including brain-derived neurotrophic factor (BDNF) [60]. Flavonoids are also known to 
modulate the activity of the Akt enzyme system (also known as $\mathrm{PKB}$ ), regulated by phosphoinositide 3-kinase (PI3K). Hesperitin, a flavonone from citrus fruits, has been observed to activate Akt/PKB and subsequently inhibits activation of proteins associated with neuronal apoptosis including apoptosis signal-regulating kinase 1 (ASK1), Bad, caspase-9 and caspase-3 [57]. Furthermore, flavonoid-elicited activation of Akt in hippocampal neurons has been observed to result in increased mRNA translation of the activity-regulated cytoskeletal-associated protein (Arc/Arg3.1) [15]. Increased Arc expression may facilitate changes in synaptic strength and morphology of dendritic spines [61], and indeed, in vitro studies have indicated that changes in neuronal morphology and dendrite growth occur in response to flavonoid supplementation [62].

\section{Neuroinflammation}

A normal inflammatory response is critical for supporting health and in particular the brain's defence against damage. However, a chronic upregulation of neuroinflammation, indicated by increased circulatory pro-inflammatory cytokines and biomarkers, may contribute to a cascade of events resulting in progressive neuronal damage [63]. Chronic neuroinflammation can interfere with proper neuronal functioning, impede episodic memory encoding and facilitate pathological accumulation and impact of $\mathrm{A} \beta$ plaques. Chronically elevated activation of pro-inflammatory cytokines, such as tumour necrosis factor (TNF- $\alpha$ ), contributes to neuronal injury through amplification of the inflammatory response [64]. Indeed, individuals with MCI have been found to have elevated circulating levels of serum TNF- $\alpha$ compared to agematched controls [65], and is over expressed in affected neural regions [66] and in cerebrospinal fluid (CSF) of individuals diagnosed with AD [67]. Furthermore, the acute phase protein, serum C-reactive protein (CRP), is associated with greater risk of dementia onset [68] and memory impairment, and has also been found to co-localise with pathological $A \beta$ and neurofibrillary tangles in the brains of AD patients $[69,70]$. Indeed, elevated plasma concentrations of CRP have been consistently found in individuals with MCI [71] and AD [72].

Neuroinflammation has further been implicated in contributing to AD pathology through increased activation of microglial and consequently elevated activation of acetyl cholinesterase (AChE) and free radical generation [73]. Indeed, findings of lower AD risk associated with long-term use of non-steroidal anti-inflammatory drugs (NSAIDs) [74] have led to increased attention turning to developing antiinflammatory pharmaceutical solutions to reduce the impact of neuroinflammation on brain disease. Flavonoids may also prevent neuroinflammation via several anti-inflammatory mechanisms, including (1) inhibiting the microglial activation of inflammatory cytokines, including TNF- $\alpha$ and IL-1 $\beta$; (2) inhibiting iNOS induction and subsequent nitric oxide production in response to glial activation; (3) inhibiting activation of NADPH oxidase and subsequent ROS generation in activated glia; and (4) downregulating activity of proinflammatory transcription factors such as NF-KB through modulation of glial and neuronal signalling pathways [75]. However, the majority of evidence from in vitro research has come from studies using single flavonoids, typically aglycones, at supraphysiological concentrations. Few studies however have investigated the anti-inflammatory effects of physiologically attainable flavonoid concentration in healthy subjects, and the findings from these are less consistent [76]. However, epicatechin and catechin were observed to inhibit $\mathrm{TNF}-\alpha$ release but not iNOS expression or nitric oxide production in primary glial cells [77], providing promising evidence that some flavanols at physiologically relevant concentrations could exert anti-inflammatory effects. In studies involving humans, higher intake of a flavonoid-rich was associated to lower levels of inflammatory biomarkers including CRP, IL-6 and adhesion factors [78]. Furthermore, total flavonoid intake as well as intake of the specific flavonols anthocyanidins and isoflavones were related to lower blood levels of CRP in a large cross-sectional epidemiological study [79]. Finally, blueberry anthocyanin given to adults aged 4074 years over 3 weeks significantly reduced plasma concentrations of NF-kB-related pro-inflammatory cytokines and chemokines (IL-4, IL-13, IL-8 and IFN- $\alpha$ ) [80]. In contrast, a short-term intervention with black tea $(900 \mathrm{~mL} /$ day, 4 weeks $)$ showed no improvements in plasma CRP concentrations in patients with coronary artery disease [81]. Furthermore, no significant effect was observed in plasma CRP or ICAM-1 levels in healthy adults consuming diets rich in berries and apples for 6 weeks [82]. The inconsistent results from these various trials on the preventive anti-inflammatory effects of flavonoid supplementation reinforce the necessity for more prospective randomised trials with larger sample sizes and under clinical conditions.

\section{Vascular Function and Angiogenesis}

The integrity of the vascular system becomes increasingly vital with increasing age. The risk factors for reduced vascular health and function, such as diabetes mellitus, smoking, hypertension and arteriosclerosis, are shared by several forms of dementia including AD [83]. There have been findings that flavonoid-rich diets are associated with lower cardiovascular risk through lowering blood pressure, increasing the bioavailability of nitric oxide [84] and improving arterial flowmediated dilation [85]. Vascular function within the brain is not only integral for the prevention of ischaemic events, but also for maintaining cerebral blood flow underpinning cognitive function. Indeed, evidence suggests that flavonoids can improve cerebrovascular blood flow through their impact on 
the peripheral and cerebral vascular system [86]. Neuroimaging studies in both healthy older [34, 35, 86, 87] and younger adults [88] have shown that the consumption of flavanol-rich cocoa could significantly enhance cerebral blood flow in response to cognitive tasks. Additionally, significantly increased perfusion in the middle and inferior right frontal gyrus was observed following the intake of a high-flavonoid citrus drink in healthy adults after $2 \mathrm{~h}$ compared to baseline and controls [89•]. These effects are particularly significant, as increased cerebrovascular function is known to facilitate adult neurogenesis [90], especially within the hippocampus, and to enhance vascularisation [91], two events important in the maintenance of cognitive performance. If such effects prove possible, then diet would have the potential not only to slow the progression of neurodegeneration and cognitive decline but also to potentially reverse cognitive impairment through stimulation of neuronal growth in the hippocampus.

\section{Interactions with the Microbiome}

The gastrointestinal tract plays a key role in protecting and promoting health, including regulating energy metabolism, acting as a barrier to potential toxic compounds present in ingested food and supporting the immune system. The functioning of microbiota in particular can directly impact physiological processes throughout the body. Research over the past two decades has indicated that the gut microbiome and its interaction with dietary compounds has important implications for human health. Dietary flavonoids can have a direct effect on the gastrointestinal tract and particularly interact with the gut microbiota. Flavonoids reach the stomach and intestine in high concentrations, enabling them to exert their most direct effects here, including potential antioxidant effects, before being processed by the liver. Flavonoids that are not absorbed in the small intestine due to their close binding with $\beta$ glucosides [92] and other sugars are then broken down in the colon by microbiota into phenolic acids and other metabolites. Flavonoids and their metabolites are understood to regulate the function of the gastrointestinal tract through direct interactions with the gut microbiota. Most notably, flavonoids can impact the composition of bacterial populations in the gastrointestinal tract, including promoting the growth of beneficial (commensal) bacteria and potentially inhibiting pathogenic strains. The impact of flavonoids on specific strains of bacteria is considered to be dependent on the molecular structure of certain classes of flavonoid [93]. For example, A-type proanthocyanidins present in cranberries have been found to inhibit the adhesion of Escherichia coli bacterial strains within the human urinary tract [94]. Quercetin has also been found to inhibit the growth of Ruminococcus gauvreauii, Bacteroides galacturonicus and Lactobacillus sp. strains [95], and flavonoids present in berries have also shown inhibitory actions against Bacillus cereus, Campylobacter jejuni, Clostridium perfingens, Helicobacter pylori, Staphylococcus aureus, Staphylococcus epidermidis and Candida albicans [96]. Conversely, a diet of apples genetically modified to have higher concentrations of flavonoids was associated with greater concentrations of beneficial strains of Bifidobacterium spp. and Bacteroides-Prevotella-Poryphyromonas in mice [97].

The interactions between flavonoids and microbiota are bidirectional, and microbiota in the gastrointestinal tract can impact the absorption and bioavailability of flavonoids present in ingested food, which integrally modifies their impact on health. In addition to gastrointestinal enzymes, microbiota are also involved in the metabolism of flavonoids. Proanthocyanidins are poorly absorbed within the gastrointestinal tract, however, once they are metabolised by the microbiota into smaller compounds such as phenolic acids that are readily absorbed [98]. These flavonoid metabolites are then able to be absorbed into the bloodstream where they are able to exert more systemic health effects. For example, the gut metabolites of anthocyanins have been observed to attenuate the adhesion of monocytes to TNF $\alpha$-activated endothelial cells, which suggests they could play a key role in preventing the development of atherosclerosis at its earliest stages [99•]. Flavonoid metabolites, particularly in certain combinations, have been suggested to be able to impact health differently to their parent flavonoid compounds [100-101, 102•]. In particular, specific combinations of flavonoid metabolites were found to significantly reduce IL-I $\beta$ secretion, suggesting further potential anti-inflammatory effects of flavonoids their metabolism [102•]. Furthermore, evidence regarding phenolic acids metabolised from anthocyanidins by microbiota has suggested that they could interfere with the assembly of $A \beta$ in rats $[103 \bullet \bullet]$. However, more work is required to more fully understand the complex interactions between flavonoids and the microbiome and to determine the exact nature of their subsequent local and systemic health benefits, particularly in humans.

\section{Conclusion}

With an ageing population, age-related cognitive decline and neurodegeneration pose a significant challenge for the future. Dementia costs to the UK alone have been estimated to be $£ 26$ billion each year, with the cost expected to double in the next 25 years to $£ 55$ billion by 2040 [104]. A reduction in age-related cognitive decline by just $1 \%$ per year would cancel out all estimated increases in the longterm care costs due to our ageing population [104]. The potential neuroprotective benefits of dietary flavonoids could provide a promising alternative strategy to combat age-related cognitive decline and pathological neurodegeneration. However, given the lack of intervention trials conducted in humans under clinical conditions, the causality 
of the relationships between flavonoid intake and these health impacts as well as their exact mechanisms is still to be established.

\section{Compliance with Ethical Standards}

Conflict of Interest Emma Flanagan, Michael Müller, Michael Hornberger and David Vauzour declare they have no conflict of interest.

Human and Animal Rights and Informed Consent This article does not contain any studies with human or animal subjects performed by any of the authors.

Open Access This article is distributed under the terms of the Creative Commons Attribution 4.0 International License (http:// creativecommons.org/licenses/by/4.0/), which permits unrestricted use, distribution, and reproduction in any medium, provided you give appropriate credit to the original author(s) and the source, provide a link to the Creative Commons license, and indicate if changes were made.

\section{References}

Papers of particular interest, published recently, have been highlighted as:

- Of importance

•. Of major importance

1. Nussbaum RL, Ellis CE. Alzheimer's disease and Parkinson's disease. N Engl J Med. 2003;348(14):1356-64. https://doi.org/ 10.1056/NEJM2003ra020003.

2. Prince M, Bryce R, Albanese E, Wimo A, Ribeiro W, Ferri CP. The global prevalence of dementia: a systematic review and metaanalysis. Alzheimers Dement. 2013;9(1):63-75 e2. https:// doi.org/10.1016/j.jalz.2012.11.007.

3. Vauzour D, Vafeiadou K, Rodriguez-Mateos A, Rendeiro C, Spencer JP. The neuroprotective potential of flavonoids: a multiplicity of effects. Genes Nutr. 2008;3(3-4):115-26. https://doi. org/10.1007/s12263-008-0091-4.

4. Gu Y, Nieves JW, Stern Y, Luchsinger JA, Scarmeas N. Food combination and Alzheimer disease risk: a protective diet. Arch Neurol. 2010;67(6):699-706. https://doi.org/10.1001/archneurol. 2010.84 .

5. Solfrizzi V, Panza F, Frisardi V, Seripa D, Logroscino G, Imbimbo BP, et al. Diet and Alzheimer's disease risk factors or prevention: the current evidence. Expert Rev Neurother. 2011;11(5):677-708. https://doi.org/10.1586/ern.11.56.

6. Dixon RA, Wahlin A, Maitland SB, Hultsch DF, Hertzog C, Backman L. Episodic memory change in late adulthood: generalizability across samples and performance indices. Mem Cogn. 2004;32(5):768-78.

7. Siedlecki KL, Salthouse TA, Berish DE. Is there anything special about the aging of source memory? Psychol Aging. 2005;20(1): 19-32. https://doi.org/10.1037/0882-7974.20.1.19.

8. Barberger-Gateau P, Raffaitin C, Letenneur L, Berr C, Tzourio C, Dartigues JF, et al. Dietary patterns and risk of dementia: the Three-City cohort study. Neurology. 2007;69(20):1921-30. https://doi.org/10.1212/01.wnl.0000278116.37320.52.

9. Kesse-Guyot E, Fezeu L, Andreeva VA, Touvier M, Scalbert A, Hercberg $\mathrm{S}$, et al. Total and specific polyphenol intakes in midlife are associated with cognitive function measured 13 years later. J Nutr. 2012;142(1):76-83. https://doi.org/10.3945/jn.111.144428.

10. Letenneur L, Proust-Lima C, Le GA, Dartigues JF, BarbergerGateau P. Flavonoid intake and cognitive decline over a 10-year period. Am J Epidemiol. 2007;165(12):1364-71.

11. Rothwell JA, Perez-Jimenez J, Neveu V, Medina-Remon A, M'Hiri N, Garcia-Lobato P, et al. Phenol-Explorer 3.0: a major update of the Phenol-Explorer database to incorporate data on the effects of food processing on polyphenol content. Database (Oxford). 2013;2013:bat070. https://doi.org/10.1093/database/ bat070.

12. Williams CM, El Mohsen MA, Vauzour D, Rendeiro C, Butler LT, Ellis JA, et al. Blueberry-induced changes in spatial working memory correlate with changes in hippocampal CREB phosphorylation and brain-derived neurotrophic factor (BDNF) levels. Free Radic Biol Med. 2008;45(3):295-305.

13. Goyarzu P, Malin DH, Lau FC, Taglialatela G, Moon WD, Jennings R, et al. Blueberry supplemented diet: effects on object recognition memory and nuclear factor-kappa $\mathrm{B}$ levels in aged rats. Nutr Neurosci. 2004;7(2):75-83. https://doi.org/10.1080/ 10284150410001710410.

14. Barros D, Amaral OB, Izquierdo I, Geracitano L, Do Carmo Bassols Raseira M, Henriques AT, et al. Behavioral and genoprotective effects of Vaccinium berries intake in mice. Pharmacol Biochem Behav. 2006;84(2):229-34. https://doi.org/ 10.1016/j.pbb.2006.05.001.

15. Ramirez MR, Izquierdo I, Do Carmo Bassols Raseira M, Zuanazzi JA, Barros D, Henriques AT. Effect of lyophilised Vaccinium berries on memory, anxiety and locomotion in adult rats. Pharmacol Res. 2005;52(6):457-62.

16. Rendeiro C, Vauzour D, Kean RJ, Butler LT, Rattray M, Spencer JP, et al. Blueberry supplementation induces spatial memory improvements and region-specific regulation of hippocampal BDNF mRNA expression in young rats. Psychopharmacology. 2012;223(3):319 30. https://doi.org/10.1007/s00213-012-2719-8.

17. Devore EE, Kang JH, Breteler MM, Grodstein F. Dietary intakes of berries and flavonoids in relation to cognitive decline. Ann Neurol. 2012; https://doi.org/10.1002/ana.23594.

18. van Praag H, Lucero MJ, Yeo GW, Stecker K, Heivand N, Zhao C, et al. Plant-derived flavanol (-)epicatechin enhances angiogenesis and retention of spatial memory in mice. J Neurosci. 2007;27(22): 5869-78. https://doi.org/10.1523/JNEUROSCI.0914-07.2007.

19. Li Q, Zhao HF, Zhang ZF, Liu ZG, Pei XR, Wang JB, et al. Longterm administration of green tea catechins prevents age-related spatial learning and memory decline in $\mathrm{C} 57 \mathrm{BL} / 6 \mathrm{~J}$ mice by regulating hippocampal cyclic amp-response element binding protein signaling cascade. Neuroscience. 2009;159(4):1208-15. https:// doi.org/10.1016/j.neuroscience.2009.02.008.

20. Alzheimer's A. 2012 Alzheimer's disease facts and figures. Alzheimers Dement. 2012;8(2):131-68. https://doi.org/10.1016/ j.jalz.2012.02.001.

21. Walsh DM, Teplow DB. Chapter 4 - Alzheimer's disease and the amyloid $\beta$-protein. In: David BT, editor. Progress in molecular biology and translational science. Academic Press; 2012. p. 101-24.

22. Petersen RC, Negash S. Mild cognitive impairment: an overview. CNS Spectr. 2008;13(1):45-53.

23. Albert MS, DeKosky ST, Dickson D, Dubois B, Feldman HH, Fox NC, et al. The diagnosis of mild cognitive impairment due to Alzheimer's disease: recommendations from the National Institute on Aging-Alzheimer's Association workgroups on diagnostic guidelines for Alzheimer's disease. Alzheimers Dement. 2011;7(3):270-9. https://doi.org/10.1016/j.jalz.2011.03.008.

24. Mitchell AJ, Shiri-Feshki M. Rate of progression of mild cognitive impairment to dementia-meta-analysis of 41 robust inception 
cohort studies. Acta Psychiatr Scand. 2009;119(4):252-65. https:// doi.org/10.1111/j.1600-0447.2008.01326.x.

25. Commenges D, Scotet V, Renaud S, Jacqmin-Gadda H, Barberger-Gateau P, Dartigues JF. Intake of flavonoids and risk of dementia. Eur J Epidemiol. 2000;16(4):357-63.

26. Price DL, Tanzi RE, Borchelt DR, Sisodia SS. Alzheimer's disease: genetic studies and transgenic models. Annu Rev Genet. 1998;32:461-93. https://doi.org/10.1146/annurev.genet.32.1.461.

27. Jones L, Harold D, Williams J. Genetic evidence for the involvement of lipid metabolism in Alzheimer's disease. Biochim Biophys Acta. 2010;1801(8):754-61. https://doi.org/10.1016/j. bbalip.2010.04.005.

28. Corder EH, Saunders AM, Strittmatter WJ, Schmechel DE, Gaskell PC, Small GW, et al. Gene dose of apolipoprotein E type 4 allele and the risk of Alzheimer's disease in late onset families. Science. 1993;261(5123):921-3.

29. Packard CJ, Westendorp RG, Stott DJ, Caslake MJ, Murray HM, Shepherd J, et al. Association between apolipoprotein E4 and cognitive decline in elderly adults. J Am Geriatr Soc. 2007;55(11):1777-85. https://doi.org/10.1111/j.1532-5415.2007. 01415.x.

30. Whitehair DC, Sherzai A, Emond J, Raman R, Aisen PS, Petersen $\mathrm{RC}$, et al. Influence of apolipoprotein $\mathrm{E}$ varepsilon4 on rates of cognitive and functional decline in mild cognitive impairment. Alzheimers Dement. 2010;6(5):412-9. https://doi.org/10.1016/j. jalz.2009.12.003.

31. Dai Q, Borenstein AR, Wu Y, Jackson JC, Larson EB. Fruit and vegetable juices and Alzheimer's disease: the Kame Project. Am J Med. 2006;119(9):751-9. https://doi.org/10.1016/j.amjmed.2006. 03.045 .

32. Field DT, Williams CM, Butler LT. Consumption of cocoa flavanols results in an acute improvement in visual and cognitive functions. Physiol Behav. 2011;103(3-4):255-60. https://doi.org/ 10.1016/j.physbeh.2011.02.013.

33. Scholey AB, French SJ, Morris PJ, Kennedy DO, Milne AL, Haskell CF. Consumption of cocoa flavanols results in acute improvements in mood and cognitive performance during sustained mental effort. J Psychopharmacol. 2010;24(10):1505-14. https:// doi.org/10.1177/0269881109106923.

34. Lamport DJ, Pal D, Moutsiana C, Field DT, Williams CM, Spencer JP, et al. The effect of flavanol-rich cocoa on cerebral perfusion in healthy older adults during conscious resting state: a placebo controlled, crossover, acute trial. Psychopharmacology. 2015;232(17):3227-34. https://doi.org/10.1007/s00213-015$3972-4$.

35. Brickman AM, Khan UA, Provenzano FA, Yeung LK, Suzuki W, Schroeter $\mathrm{H}$, et al. Enhancing dentate gyrus function with dietary flavanols improves cognition in older adults. Nat Neurosci. 2014;17(12):1798-803. https://doi.org/10.1038/nn.3850.

36. Krikorian R, Nash TA, Shidler MD, Shukitt-Hale B, Joseph JA. Concord grape juice supplementation improves memory function in older adults with mild cognitive impairment. Br J Nutr. 2010;103(5):730-4. https://doi.org/10.1017/S0007114509992364.

37. Krikorian R, Shidler MD, Nash TA, Kalt W, Vinqvist-Tymchuk MR, Shukitt-Hale B, et al. Blueberry supplementation improves memory in older adults. J Agric Food Chem. 2010;58(7):39964000. https://doi.org/10.1021/j99029332.

38. Desideri G, Kwik-Uribe C, Grassi D, Necozione S, Ghiadoni L, Mastroiacovo D, et al. Benefits in cognitive function, blood pressure, and insulin resistance through cocoa flavanol consumption in elderly subjects with mild cognitive impairment: the Cocoa, Cognition, and Aging (CoCoA) study. Hypertension. 2012;60(3): 794-801. https://doi.org/10.1161/HYPERTENSIONAHA.112. 193060.
39. Williams RJ, Spencer JP, Rice-Evans C. Flavonoids: antioxidants or signalling molecules? Free Radic Biol Med. 2004;36(7):838 49. https://doi.org/10.1016/j.freeradbiomed.2004.01.001.

40. Savonenko AV, Melnikova T, Hiatt A, Li T, Worley PF, Troncoso JC, et al. Alzheimer's therapeutics: translation of preclinical science to clinical drug development. Neuropsychopharmacology. 2012;37(1):261-77. https://doi.org/10.1038/npp.2011.211.

41. Walsh DM, Selkoe DJ. A beta oligomers - a decade of discovery. J Neurochem. 2007;101(5):1172-84. https://doi.org/10.1111/j. 1471-4159.2006.04426.x.

42. Mori T, Rezai-Zadeh K, Koyama N, Arendash GW, Yamaguchi H, Kakuda N, et al. Tannic acid is a natural beta-secretase inhibitor that prevents cognitive impairment and mitigates Alzheimer-like pathology in transgenic mice. J Biol Chem. 2012; https://doi.org/ 10.1074/jbc.M111.294025.

43. Williams RJ, Spencer JP. Flavonoids, cognition, and dementia: actions, mechanisms, and potential therapeutic utility for Alzheimer disease. Free Radic Biol Med. 2012;52(1):35-45. https://doi.org/10.1016/j.freeradbiomed.2011.09.010.

44. Rezai-Zadeh K, Arendash GW, Hou H, Fernandez F, Jensen M, Runfeldt M, et al. Green tea epigallocatechin-3-gallate (EGCG) reduces beta-amyloid mediated cognitive impairment and modulates tau pathology in Alzheimer transgenic mice. Brain Res. 2008;1214:177-87. https://doi.org/10.1016/j.brainres.2008.02. 107.

45. Li Q, Zhao HF, Zhang ZF, Liu ZG, Pei XR, Wang JB, et al. Longterm green tea catechin administration prevents spatial learning and memory impairment in senescence-accelerated mouse prone- 8 mice by decreasing Abeta1-42 oligomers and upregulating synaptic plasticity-related proteins in the hippocampus. Neuroscience. 2009;163(3):741-9. https://doi.org/10.1016/j. neuroscience.2009.07.014.

46. Ono K, Condron MM, Ho L, Wang J, Zhao W, Pasinetti GM, et al. Effects of grape seed-derived polyphenols on amyloid betaprotein self-assembly and cytotoxicity. J Biol Chem. 2008;283(47):32176-87. https://doi.org/10.1074/jbc. M806154200.

47. Onozuka H, Nakajima A, Matsuzaki K, Shin RW, Ogino K, Saigusa D, et al. Nobiletin, a citrus flavonoid, improves memory impairment and Abeta pathology in a transgenic mouse model of Alzheimer's disease. J Pharmacol Exp Ther. 2008;326(3):739-44. https://doi.org/10.1124/jpet.108.140293.

48. Amit T, Avramovich-Tirosh Y, Youdim MB, Mandel S. Targeting multiple Alzheimer's disease etiologies with multimodal neuroprotective and neurorestorative iron chelators. FASEB J. 2008;22(5):1296-305. https://doi.org/10.1096/fj.07-8627rev.

49. Ehrnhoefer DE, Bieschke J, Boeddrich A, Herbst M, Masino L, Lurz R, et al. EGCG redirects amyloidogenic polypeptides into unstructured, off-pathway oligomers. Nat Struct Mol Biol. 2008;15(6):558-66. https://doi.org/10.1038/nsmb.1437.

50. Obregon DF, Rezai-Zadeh K, Bai Y, Sun N, Hou H, Ehrhart J, et al. ADAM10 activation is required for green tea (-)-epigallocatechin-3-gallate-induced alpha-secretase cleavage of amyloid precursor protein. J Biol Chem. 2006;281(24):16419-27. https://doi. org/10.1074/jbc.M600617200.

51.• Dal-Pan A, Dudonne S, Bourassa P, Bourdoulous M, Tremblay C, Desjardins Y, et al. Cognitive-enhancing effects of a polyphenolsrich extract from fruits without changes in neuropathology in an animal model of Alzheimer's disease. J Alzheimers Dis. 2017;55(1):115-35. https://doi.org/10.3233/JAD-160281. This study by Dal-Pan et al. (2017) showed that the consumption of polyphenol-rich extracts prevented memory impairment in an AD mouse model, and furthermore that these effects were observed in the absence of any direct impact on amyloid plaques or neurofibrillary tangles. These findings suggest that 
the protective benefits of flavonoids extend beyond interactions with classical AD neuropathology.

52. Schroeter H, Bahia P, Spencer JPE, Sheppard O, Rattray M, RiceEvans C, et al. (-)-epicatechin stimulates ERK-dependent cyclic AMP response element activity and upregulates GLUR2 in cortical neurons. J Neurochem. 2007;101:1596-606.

53. Vauzour D, Vafeiadou K, Rice-Evans C, Williams RJ, Spencer JP. Activation of pro-survival Akt and ERK1/2 signalling pathways underlie the anti-apoptotic effects of flavanones in cortical neurons. J Neurochem. 2007;103(4):1355-67. https://doi.org/10. 1111/j.1471-4159.2007.04841.x.

54. Vauzour D. Dietary polyphenols as modulators of brain functions: biological actions and molecular mechanisms underpinning their beneficial effects. Oxidative Med Cell Longev. 2012;2012: 914273. https://doi.org/10.1155/2012/914273.

55. Schroeter H, Boyd C, Spencer JP, Williams RJ, Cadenas E, RiceEvans C. MAPK signaling in neurodegeneration: influences of flavonoids and of nitric oxide. Neurobiol Aging. 2002;23(5): 861-80.

56. Schroeter H, Spencer JP, Rice-Evans C, Williams RJ. Flavonoids protect neurons from oxidized low-density-lipoprotein-induced apoptosis involving c-Jun N-terminal kinase (JNK), c-Jun and caspase-3. Biochem J. 2001;358(Pt 3):547-57.

57. Vauzour D, VafeiAdou K, Rice-Evans C, Williams RJ, Spencer JP. Activation of pro-survival Akt and ERK1/2 signalling pathways underlie the anti-apoptotic effects of flavanones in cortical neurons. J Neurochem. 2007;103(4):1355-67.

58. Levites Y, Youdim MB, Maor G, Mandel S. Attenuation of 6hydroxydopamine (6-OHDA)-induced nuclear factor-kappaB (NF-kappaB) activation and cell death by tea extracts in neuronal cultures. Biochem Pharmacol. 2002;63(1):21-9.

59. Impey S, Smith DM, Obrietan K, Donahue R, Wade C, Storm DR. Stimulation of cAMP response element (CRE)-mediated transcription during contextual learning. Nat Neurosci. 1998;1(7): 595-601. https://doi.org/10.1038/2830.

60. Tully T, Bourtchouladze R, Scott R, Tallman J. Targeting the CREB pathway for memory enhancers. Nat Rev Drug Discov. 2003;2(4):267-77. https://doi.org/10.1038/nrd1061.

61. Waltereit R, Dammermann B, Wulff P, Scafidi J, Staubli U, Kauselmann G, et al. Arg3.1/Arc mRNA induction by Ca2+ and cAMP requires protein kinase $\mathrm{A}$ and mitogen-activated protein kinase/extracellular regulated kinase activation. J Neurosci. 2001;21(15):5484-93.

62. Reznichenko L, Amit T, Youdim MB, Mandel S. Green tea polyphenol (-)-epigallocatechin-3-gallate induces neurorescue of longterm serum-deprived PC12 cells and promotes neurite outgrowth. J Neurochem. 2005;93(5):1157-67. https://doi.org/10.1111/j. 1471-4159.2005.03085.x.

63. Agostinho P, Cunha RA, Oliveira C. Neuroinflammation, oxidative stress and the pathogenesis of Alzheimer's disease. Curr Pharm Des. 2010;16(25):2766-78.

64. Calder PC, Albers R, Antoine JM, Blum S, Bourdet-Sicard R, Ferns GA, et al. Inflammatory disease processes and interactions with nutrition. Br J Nutr. 2009;101(Suppl 1):S1-45. https://doi. org/10.1017/S0007114509377867.

65. Trollor JN, Smith E, Baune BT, Kochan NA, Campbell L, Samaras K, et al. Systemic inflammation is associated with MCI and its subtypes: the Sydney Memory and Aging Study. Dement Geriatr Cogn Disord. 2010;30(6):569-78. https://doi.org/10.1159/ 000322092.

66. Akiyama H, Barger S, Barnum S, Bradt B, Bauer J, Cole GM, et al. Inflammation and Alzheimer's disease. Neurobiol Aging. 2000;21(3):383-421.

67. Tarkowski E, Liljeroth AM, Minthon L, Tarkowski A, Wallin A, Blennow K. Cerebral pattern of pro- and anti-inflammatory cytokines in dementias. Brain Res Bull. 2003;61(3):255-60.
68. Kravitz BA, Corrada MM, Kawas CH. Elevated C-reactive protein levels are associated with prevalent dementia in the oldest-old. Alzheimers Dement. 2009;5(4):318-23. https://doi.org/10.1016/j. jalz.2009.04.1230.

69. Duong T, Nikolaeva M, Acton PJ. C-reactive protein-like immunoreactivity in the neurofibrillary tangles of Alzheimer's disease. Brain Res. 1997;749(1):152-6.

70. Wood JA, Wood PL, Ryan R, Graff-Radford NR, Pilapil C, Robitaille Y, et al. Cytokine indices in Alzheimer's temporal cortex: no changes in mature IL-1 beta or IL-1RA but increases in the associated acute phase proteins IL-6, alpha 2-macroglobulin and C-reactive protein. Brain Res. 1993;629(2):245-52.

71. Roberts RO, Geda YE, Knopman DS, Boeve BF, Christianson TJ, Pankratz VS, et al. Association of C-reactive protein with mild cognitive impairment. Alzheimers Dement. 2009;5(5):398-405. https://doi.org/10.1016/j.jalz.2009.01.025.

72. Zaciragic A, Lepara O, Valjevac A, Arslanagic S, Fajkic A, Hadzovic-Dzuvo A, et al. Elevated serum C-reactive protein concentration in Bosnian patients with probable Alzheimer's disease. J Alzheimers Dis. 2007;12(2):151-6.

73. Williams P, Sorribas A, Howes MJ. Natural products as a source of Alzheimer's drug leads. Nat Prod Rep. 2011;28(1):48-77. https:// doi.org/10.1039/c0np00027b.

74. Szekely CA, Thorne JE, Zandi PP, Ek M, Messias E, Breitner JC, et al. Nonsteroidal anti-inflammatory drugs for the prevention of Alzheimer's disease: a systematic review. Neuroepidemiology. 2004;23(4):159-69. https://doi.org/10.1159/000078501.

75. Spencer JP, Vafeiadou K, Williams RJ, Vauzour D. Neuroinflammation: modulation by flavonoids and mechanisms of action. Mol Asp Med. 2012;33(1):83-97. https://doi.org/10. 1016/j.mam.2011.10.016.

76. Spilsbury A, Vauzour D, Spencer JP, Rattray M. Regulation of NF-kappaB activity in astrocytes: effects of flavonoids at dietary-relevant concentrations. Biochem Biophys Res Commun. 2012;418(3):578-83. https://doi.org/10.1016/j.bbrc.2012.01.081.

77. Vafeiadou K, Vauzour D, Lee HY, Rodriguez-Mateos A, Williams RJ, Spencer JP. The citrus flavanone naringenin inhibits inflammatory signalling in glial cells and protects against neuroinflammatory injury. Arch Biochem Biophys. 2009;484(1): 100-9. https://doi.org/10.1016/j.abb.2009.01.016.

78. Nanri A, Yoshida D, Yamaji T, Mizoue T, Takayanagi R, Kono S. Dietary patterns and C-reactive protein in Japanese men and women. Am J Clin Nutr. 2008;87(5):1488-96.

79. Chun OK, Chung SJ, Claycombe KJ, Song WO. Serum Creactive protein concentrations are inversely associated with dietary flavonoid intake in U.S. adults. J Nutr. 2008;138(4):753-60.

80. Karlsen A, Retterstol L, Laake P, Paur I, Bohn SK, Sandvik L, et al. Anthocyanins inhibit nuclear factor-kappaB activation in monocytes and reduce plasma concentrations of proinflammatory mediators in healthy adults. J Nutr. 2007;137(8): 1951-4.

81. Widlansky ME, Duffy SJ, Hamburg NM, Gokce N, Warden BA, Wiseman S, et al. Effects of black tea consumption on plasma catechins and markers of oxidative stress and inflammation in patients with coronary artery disease. Free Radic Biol Med. 2005;38(4):499-506. https://doi.org/10.1016/j.freeradbiomed. 2004.11.013.

82. Freese R, Vaarala O, Turpeinen AM, Mutanen M. No difference in platelet activation or inflammation markers after diets rich or poor in vegetables, berries and apple in healthy subjects. Eur J Nutr. 2004;43(3):175-82. https://doi.org/10.1007/s00394-004-0456-4.

83. Breteler MM. Vascular risk factors for Alzheimer's disease: an epidemiologic perspective. Neurobiol Aging. 2000;21(2):153-60.

84. Grassi D, Desideri G, Necozione S, Lippi C, Casale R, Properzi G, et al. Blood pressure is reduced and insulin sensitivity increased in 
glucose-intolerant, hypertensive subjects after 15 days of consuming high-polyphenol dark chocolate. J Nutr. 2008;138(9):1671-6.

85. Balzer J, Rassaf T, Heiss C, Kleinbongard P, Lauer T, Merx M, et al. Sustained benefits in vascular function through flavanolcontaining cocoa in medicated diabetic patients a double-masked, randomized, controlled trial. J Am Coll Cardiol. 2008;51(22): 2141-9. https://doi.org/10.1016/j.jacc.2008.01.059.

86. Sorond FA, Lipsitz LA, Hollenberg NK, Fisher ND. Cerebral blood flow response to flavanol-rich cocoa in healthy elderly humans. Neuropsychiatr Dis Treat. 2008;4(2):433-40.

87. Sorond FA, Hurwitz S, Salat DH, Greve DN, Fisher ND. Neurovascular coupling, cerebral white matter integrity, and response to cocoa in older people. Neurology. 2013;81(10):904-9. https://oi.org/10.1212/WNL.0b013e3182a351aa.

88. Francis ST, Head K, Morris PG, Macdonald IA. The effect of flavanol-rich cocoa on the fMRI response to a cognitive task in healthy young people. J Cardiovasc Pharmacol. 2006;47(Suppl 2): S215-20.

89. Lamport DJ, Pal D, Macready AL, Barbosa-Boucas S, Fletcher JM, Williams CM, et al. The effects of flavanone-rich citrus juice on cognitive function and cerebral blood flow: an acute, randomised, placebo-controlled cross-over trial in healthy, young adults. Br J Nutr. 2016;116(12):2160-8. https://doi.org/10.1017/ S000711451600430X. This study by Lamport et al. (2016) showed significant increases in inferior and middle right frontal regional perfusion as well as some cognitive enhancement only $2 \mathrm{~h}$ following consumption of a high-flavonone drink in healthy young adults, compared to baseline and controls. These findings suggest that a high intake of flavonoids could produce efficient and striking effects on brain vascular function.

90. Gage FH. Mammalian neural stem cells. Science. 2000;287(5457): $1433-8$.

91. Zhao C, Deng W, Gage FH. Mechanisms and functional implications of adult neurogenesis. Cell. 2008;132(4):645-60. https://doi. org/10.1016/j.cell.2008.01.033.

92. Hollman PCH. Absorption, bioavailability, and metabolism of flavonoids. Pharm Biol. 2004;42(sup1):74-83. https://doi.org/10. 1080/13880200490893492.

93. Xie Y, Yang W, Tang F, Chen X, Ren L. Antibacterial activities of flavonoids: structure-activity relationship and mechanism. Curr Med Chem. 2015;22(1):132-49.

94. Howell AB, Reed JD, Krueger CG, Winterbottom R, Cunningham DG, Leahy M. A-type cranberry proanthocyanidins and uropathogenic bacterial anti-adhesion activity. Phytochemistry. 2005;66(18):2281-91. https://doi.org/10.1016/j.phytochem.2005. 05.022 .

95. Duda-Chodak A. The inhibitory effect of polyphenols on human gut microbiota. J Physiol Pharmacol. 2012;63(5):497-503.

96. Nohynek LJ, Alakomi HL, Kahkonen MP, Heinonen M, Helander IM, Oksman-Caldentey KM, et al. Berry phenolics: antimicrobial properties and mechanisms of action against severe human pathogens. Nutr Cancer. 2006;54(1):18-32. https://doi.org/10. 1207/s15327914nc5401 4.

97. Espley RV, Butts CA, Laing WA, Martell S, Smith H, McGhie TK, et al. Dietary flavonoids from modified apple reduce inflammation markers and modulate gut microbiota in mice-3. J Nutr. 2013;144(2):146-54.

98. Zhang L, Wang Y, Li D, Ho C-T, Li J, Wan X. The absorption, distribution, metabolism and excretion of procyanidins. Food Funct. 2016;7(3):1273-81.

99. Krga I, Monfoulet L-E, Konic-Ristic A, Mercier S, Glibetic M, Morand $\mathrm{C}$, et al. Anthocyanins and their gut metabolites reduce the adhesion of monocyte to TNF $\alpha$-activated endothelial cells at physiologically relevant concentrations. Arch Biochem Biophys. 2016;599:51-9. Krga et al. (2016) demonstrated the ability of anthocyanidin metabolites produced via metabolism by gut microbiota modulated the adhesion of monocytes to human endothelial cells. These findings suggest that flavonoids metabolised by gut microbiota could directly impact the development of atherosclerosis development in its early stages of development.

100. Verbeek R, van Tol EA, van Noort JM. Oral flavonoids delay recovery from experimental autoimmune encephalomyelitis in SJL mice. Biochem Pharmacol. 2005;70(2):220-8. https://doi. org/10.1016/j.bcp.2005.04.041.

101. Wang P, Chen H, Zhu Y, McBride J, Fu J, Sang S. Oat avenanthramide- $\mathrm{C}(2 \mathrm{c})$ is biotransformed by mice and the human microbiota into bioactive metabolites-3. J Nutr. 2014;145(2): 239-45.

102. di Gesso JL, Kerr JS, Zhang Q, Raheem S, Yalamanchili SK, O'hagan D, et al. Flavonoid metabolites reduce tumor necrosis factor- $\alpha$ secretion to a greater extent than their precursor compounds in human THP-1 monocytes. Mol Nutr Food Res. 2015;59(6):1143-54. This study by di Gesso et al. (2015) demonstrated that certain combinations of flavonoid metabolites significantly reduced inflammatory cytokine activation beyond their parent flavonoids or their metabolites on their own. These findings suggest that specific combinations of flavonoids could produce optimal anti-inflammatory effects beyond that of their constituents.

103.• Wang D, Ho L, Faith J, Ono K, Janle EM, Lachcik PJ, et al. Role of intestinal microbiota in the generation of polyphenol-derived phenolic acid mediated attenuation of Alzheimer's disease betaamyloid oligomerization. Mol Nutr Food Res. 2015;59(6):102540. https://doi.org/10.1002/mnfr.201400544. Wang et al. (2015) demonstrated that metabolites from a high-flavonoid grape seed extract metabolised by gut microbiota significantly interfered with the assembly of neurotoxic $A \beta$ plaques. These findings suggest that gut microbiota could play a key role in modifying the impact of flavonoids on classical AD neuropathology development.

104. Prince M, Knapp M, Guerchet M, McCrone P, Prina M, ComasHerrera A, et al. Dementia UK: update. Alzheimer's Soc. 2014; 